\title{
Call for 2020 Annual Meeting Proposals
}

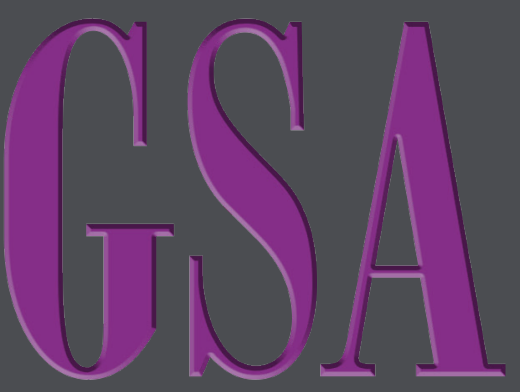

THE GEOLOGICAL SOCIETY OF AMERICA ${ }^{\circledR}$
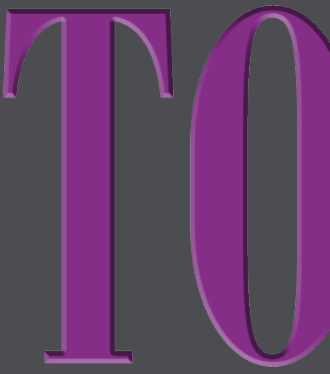

VOL. 29, NO. 12

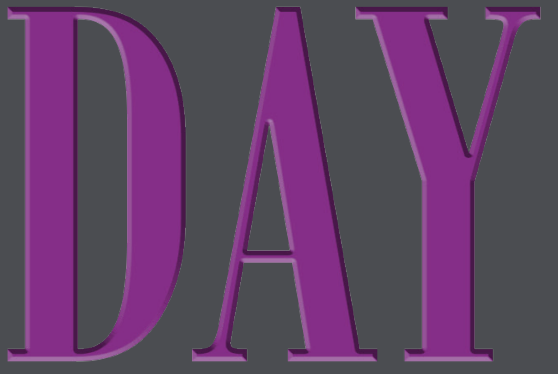

DECEMBER 2019

\section{The Faint Young Sun Problem Revisited}

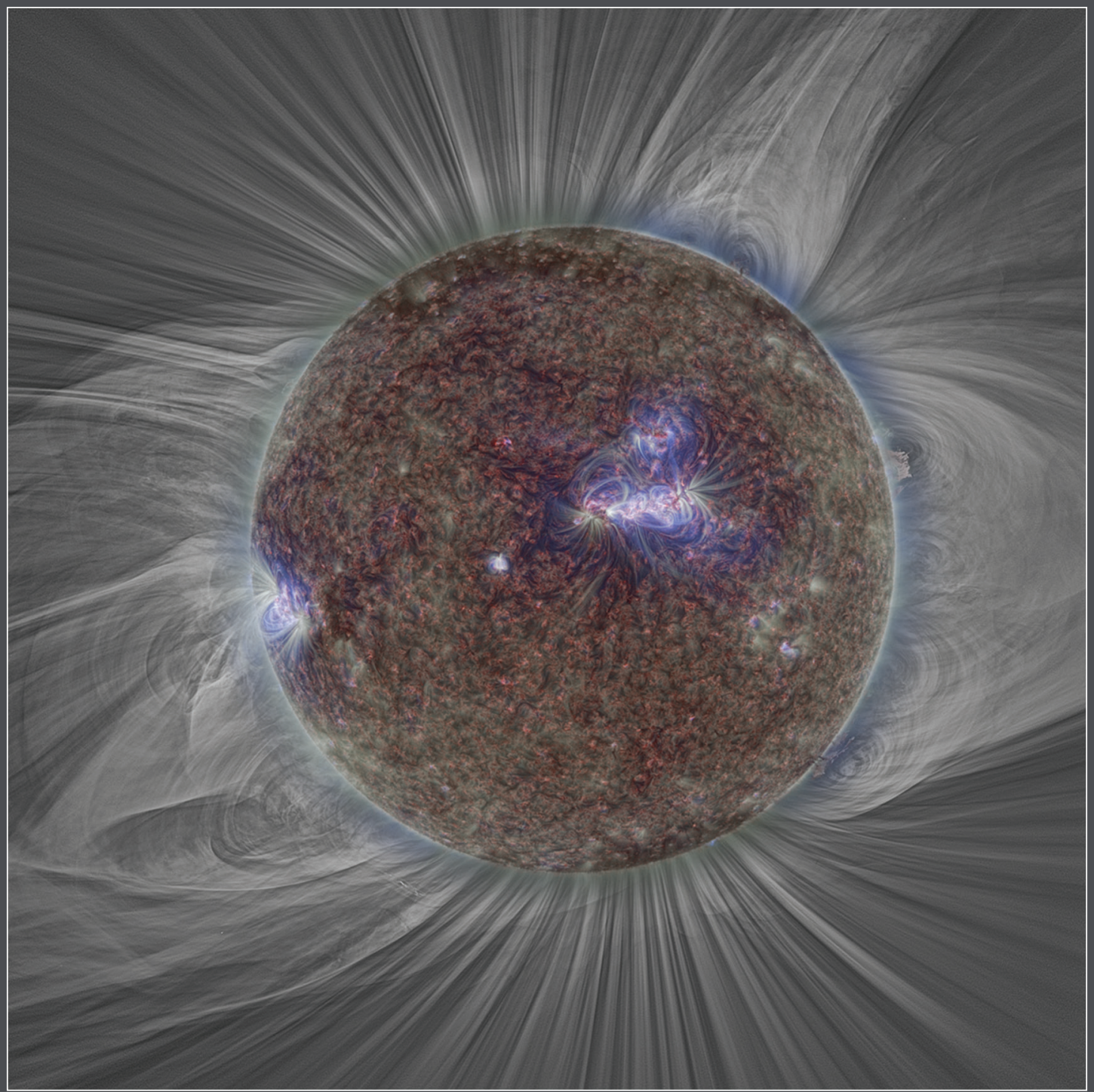




\section{The Faint Young Sun Problem Revisited}

\section{Jon Spencer, Dept. of Geosciences, University of Arizona, Tucson, Arizona 85721, USA, spencer7@email.arizona.edu}

\begin{abstract}
Earth and Mars should have been frozen worlds in their early history because of lower solar luminosity but were not, which challenges our understanding of early atmospheres and surface conditions and/or our understanding of solar evolution. This is known as the "faint young
\end{abstract} Sun problem." One resolution to the problem is that the Sun was more massive and luminous in its youth before blowing off mass. Astrophysical studies of stellar evolution and behavior, however, including recent analysis of Kepler space-telescope data, indicate that mass loss is both insufficient and occurs too early to allow for a more luminous Sun after ca. $4 \mathrm{Ga}$. Alternatively, greenhouse gases were surprisingly effective at warming young Earth and Mars. High concentrations of $\mathrm{CO}_{2}$ with the possible addition of biogenic $\mathrm{CH}_{4}$ are likely dominant factors promoting open-water conditions on Archean Earth. Evidence of precipitation and flowing water on young Mars, including river valleys thousands of kilometers long, is more problematic. Recent studies indicate that 3-4 Ga river valleys and delta deposits in crater lakes could have been produced in $<\sim 10^{7}$ years. Highly transient warm periods during times of favorable orbital parameters possibly led to brief melting under otherwise icy conditions. Seasonal melting and runoff would be more likely with $\sim 1 \%-10 \%$ atmospheric $\mathrm{H}_{2}$ and $\mathrm{CH}_{4}$, perhaps derived from serpentinization of olivine in the martian crust and released from frozen ground by impacts and volcanism, and/or derived directly from volcanic outgassing. The recently recognized effectiveness of hydrogen and methane at absorbing infrared radiation in a thick $\mathrm{CO}_{2}$-dominated atmosphere, in a process known as "collision-induced absorption," is probably essential to the solution to the faint young Sun problem for Mars.

\section{INTRODUCTION}

The basic concepts involved in stellarenergy generation were known by the 1950s and include the insight that stellar luminosity gradually increases over time because of increasing density in stellar cores resulting directly from thermonuclear fusion (e.g., Burbidge et al., 1957)

(Fig. 1). Solar luminosity at birth was calculated to be $\sim 70 \%$ of modern luminosity. The idea that Earth should have geologic evidence of its presumably frozen youth was gradually determined to be inconsistent with growing evidence for liquid water at the surface of Archean Earth. The problem was first addressed by Sagan and Mullen (1972), who proposed that atmospheric ammonia was crucial to early warming. More recent robotic exploration of Mars similarly indicates surprisingly warm and wet conditions during its early geologic history. The discrepancy between low solar-energy production and warm early Earth and Mars is known as the "faint young Sun problem" (Ulrich, 1975; Feulner, 2012). This article is a brief review of solar evolution and the faint young Sun problem for Earth and Mars that highlights recent developments.

\section{STELLAR ENERGY PRODUCTION}

Stars form by gravitational contraction of clouds of interstellar gas dominated by hydrogen. During contraction and adiabatic heating, increasing stellar energy production by nuclear fusion of hydrogen into helium eventually terminates gravitational contraction (e.g., Haxton et al., 2013). Over millions of years, helium produced by fusion of hydrogen accumulates in the cores of stars and increases core density, causing gravitational contraction and adiabatic heating which, in turn, raise fusion rates and energy generation. This process occurs gradually and continuously, resulting in increasing core temperature and total luminosity (Fig. 1) (Bahcall et al., 2001). The Sun began with $\sim 71 \%$ hydrogen

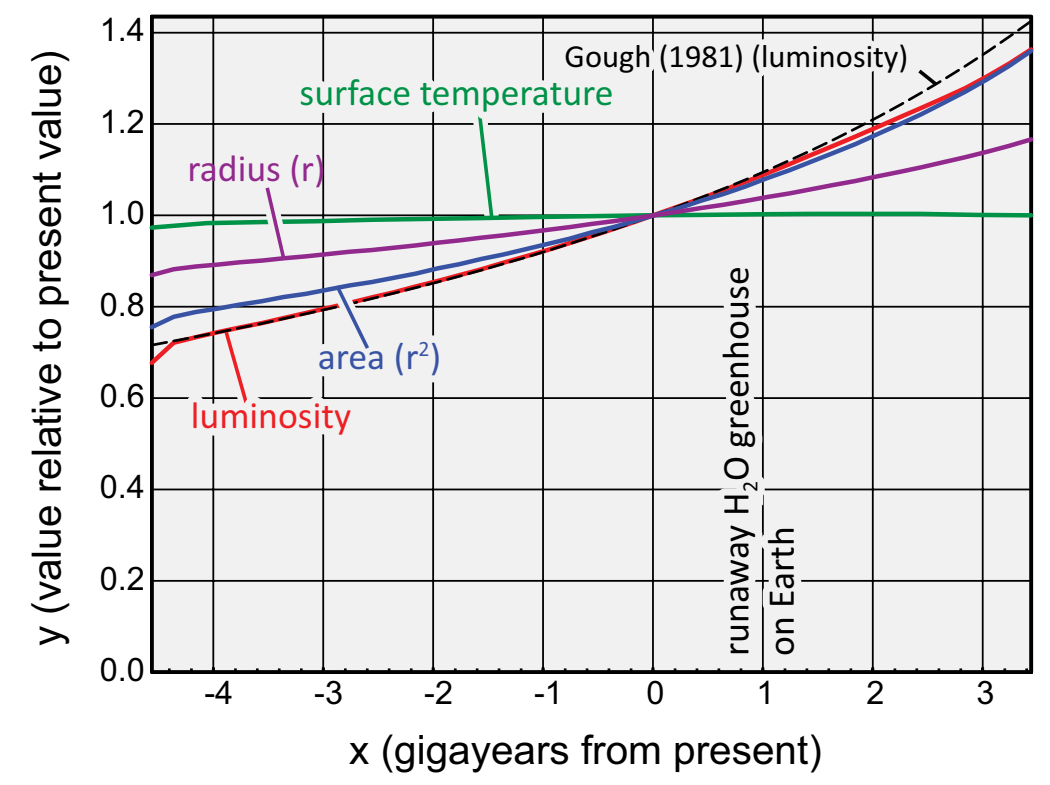

Figure 1. Evolution of solar properties (from Bahcall et al., 2001). A simple approximation of solarluminosity evolution (Equation 1 of Gough, 1981) is also shown. 
Figure 2. Known or hypothetical evolution of the Sun, Earth, and Mars. (A) Star clusters, each containing stars of similar age, are plotted against rotation rate (Rebull et al., 2016, 2017; Meibom et al., 2009, 2011, 2015; Hartman et al., 2009). These are plotted as proxies for solar evolution, so cluster age on the horizontal axis is plotted as distance from the left edge of the graph rather than the right edge. Curve showing approximate spindown rate is from Ayres (1997; $t$ = time since cluster birth). (B) Ultraviolet and $\mathrm{X}$-ray radiation fluxes inferred for the Sun over time based on measured fluxes from nearby stars with approximate solar mass but different ages (modified from Figure 8 of Ribas et al., 2005). Current radiation flux $=1$. (C) Evolution of solar luminosity for initial solar mass equal to, or slightly greater than, modern solar mass. The rate of mass loss is shown as proportional to the rate of spindown of solar type stars as shown in (A). Current luminosity $=\mathbf{1 . 0}$. Blue area at 3.2-3.5 Ga represents calculated luminosity $(\sim 77 \%-79 \%$ of modern) at the time of deposition of four stromatolite and microbial mat fossil units in northwest Australia and South Africa. (D) Some events in Earth history that reflect climate and atmospheric composition, including ages and names of Archean stromatolite and microbial mat deposits older than ca. 2.7 Ga and ages and names of glacial deposits older than ca. 2.0 Ga. Archean glacial deposits from Young et al. (1998; Mozaan), Ojakangas et al. (2014; Talya), and de Wit and Furnes (2016; Noisy) (cg-conglomerate). (E) Some events in Mars history. Pre-Noachian magnetization of the martian crust ended before formation of the Hellas impact basin. Noachian to early Hesperian highland valley networks formed after the large impact basins.

in its core and now has $\sim 34 \%$. The core will continue to contract, while the convecting outer layer will expand due to greater energy output from the core.

\section{A BRIGHT YOUNG SUN?}

Difficulties in identifying the causes of warm climates on young Earth and Mars provoked consideration of a more massive and therefore more luminous young Sun. Specifically, if the Sun was 4\%-5\% more massive at its birth, before blowing off mass as solar wind and coronal mass ejections, it could have provided elevated luminosity to warm the young planets to approximately modern temperatures (Fig. 2C) (Whitmire et al., 1995; Sackmann and Boothroyd, 2003). This is plausible because stellar luminosity is very sensitive to stellar mass. For a roughly solarmass star, absolute luminosity scales to almost the fifth power of solar mass, while the greater gravitational attraction of a more massive star reduces orbital radius proportional to mass. These factors together result in insolation at Earth and Mars that scales to almost the seventh power of solar mass such that a $1 \%$ greater solar mass would result in $\sim 7 \%$ greater insolation for orbiting planets
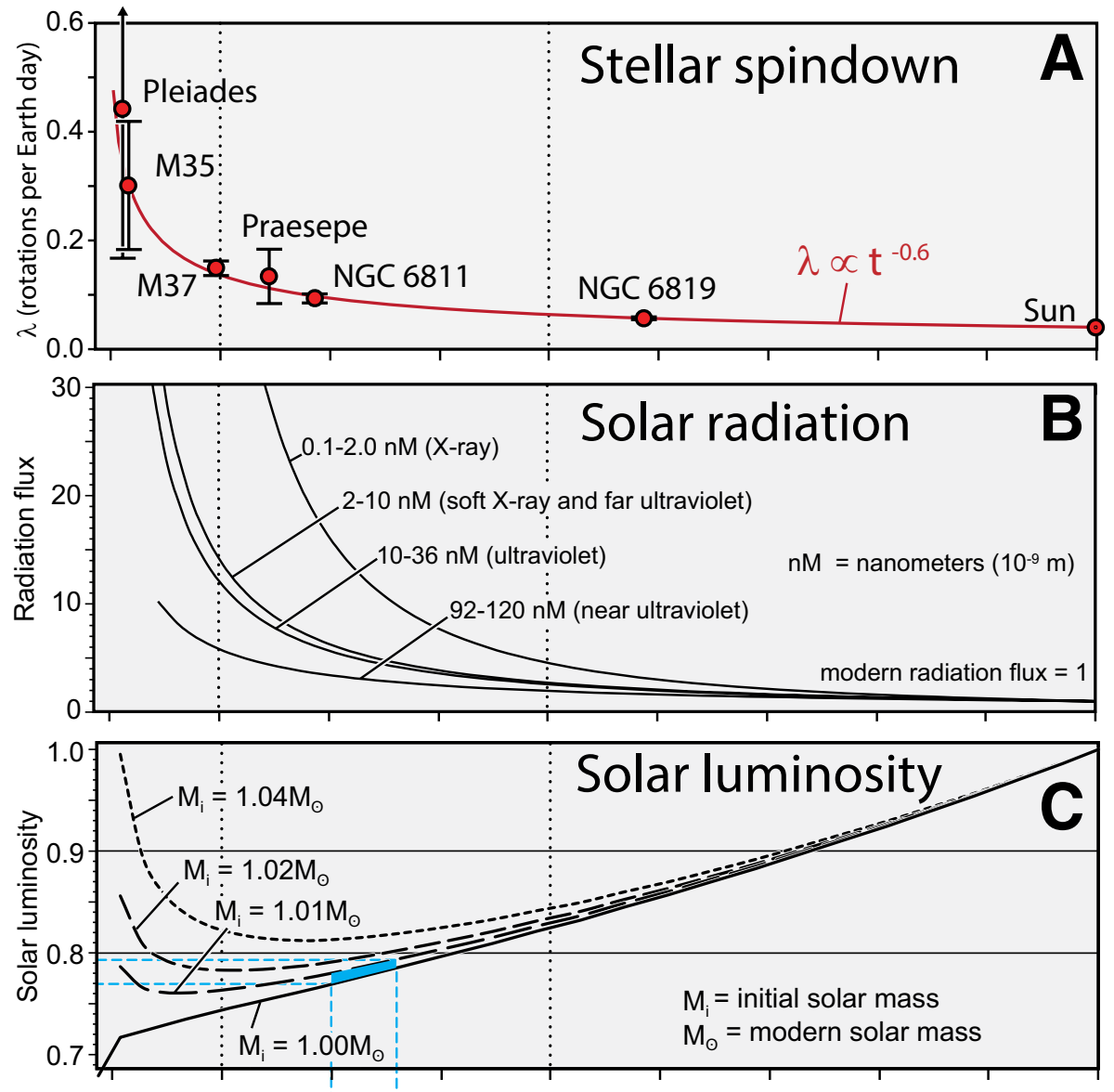

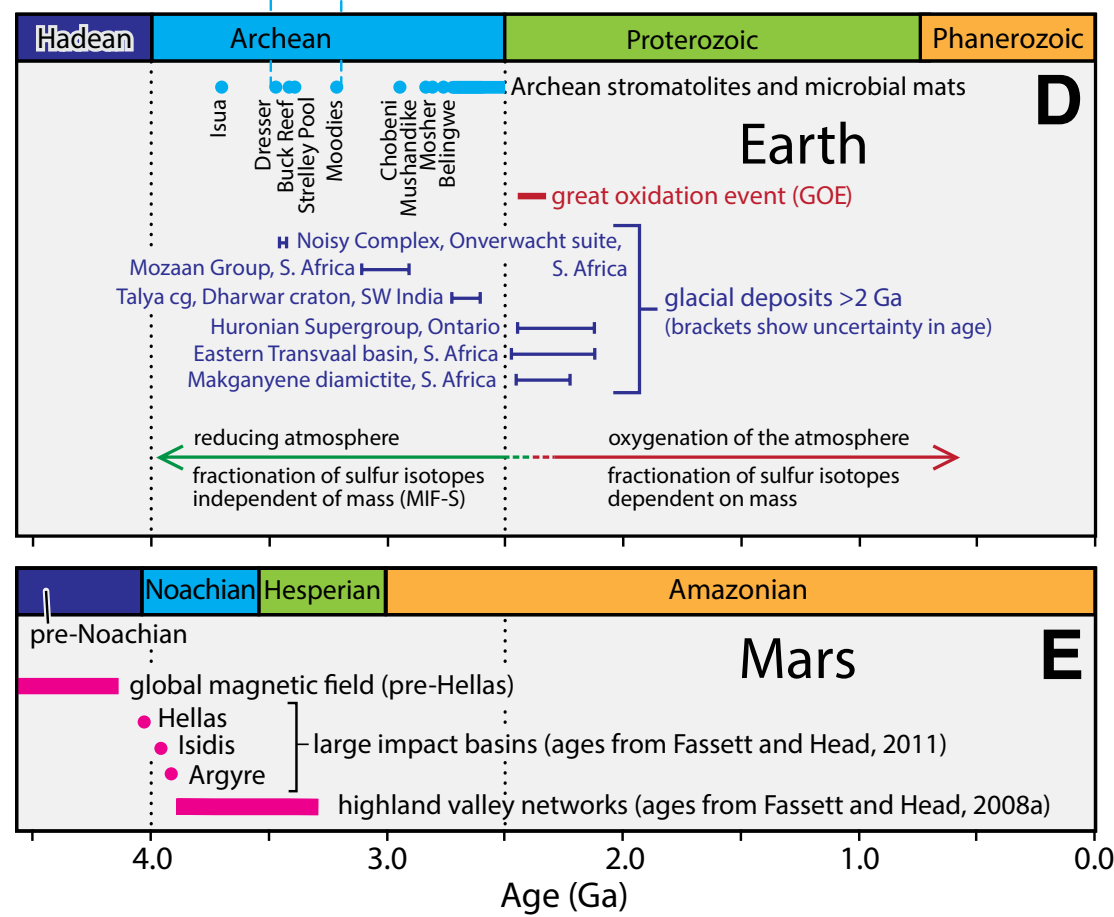

(1.01 raised to the 6.75 power $\approx 1.07$; Minton and Malhotra, 2007).

The angular momentum of spinning stars is gradually carried away by stellar winds. This is effective because rotating stellar magnetic fields sweep through stellar winds and accelerate the winds circumferentially, thereby flinging the winds away and transferring angular momentum from the star to the wind. 
Loss of angular momentum is more effective when stars spin faster, because magnetic fields are generally stronger and sweep through stellar winds faster, and because coronal mass ejections are more common (e.g., Gallet and Bouvier, 2015).

Studies of star populations in clusters in which all the stars have similar age indicate that most stellar spindown, and by inference mass loss, occurs during the first few hundred million years of a star's life (Fig. 2A) (Skumanich, 1972; Ayres, 1997). This interpretation was strengthened by recent studies using data from the Kepler planet-finder satellite mission (active 2009-2018). The Kepler telescope was designed to detect changes in stellar luminosity resulting from passage of planets in front of stars but also identified luminosity variations due to transit of starspots on stellar surfaces. This allowed determination of rotation periods for thousands of stars and accurate representation of stellar spindown rates (Fig. 2A) (Meibom et al., 2011, 2015; Rebull et al., 2017). It appears from these studies that, if the Sun did have greater mass during its youth, it would have lost most of that additional mass during rapid spindown before deposition of Archean algal stromatolites on Earth and Noachian river-channel incision and lakedelta deposition on Mars (Figs. 2C-2E).

\section{SOLAR RADIATION OVER TIME}

Short-wavelength solar radiation was stronger during the Sun's youth, which further complicates warming scenarios because some greenhouse gases such as methane are readily photolyzed (broken down) by such radiation or by free radicals produced by photolysis of other gases (Catling and Kasting, 2017). Six nearby stars similar in mass to the Sun, but with a range of ages, were identified by Ribas et al. (2005) and used to estimate radiation characteristics of the Sun over time (Fig. 2B). Short-wavelength radiation, especially far ultraviolet and X-ray, is significantly more intense for younger stars because their faster rotation rate increases the accumulation of magnetic-field energy in stellar envelopes, which in turn results in greater short-wavelength radiation from stellar surfaces and coronae.

\section{EARTH}

Solar luminosity is calculated to have been $\sim 77 \%-79 \%$ of its current value at $3.2-3.5 \mathrm{Ga}$, when at least four different rock units were deposited during openwater, probably sunlit conditions (Figs. 2C and 2D). If Earth absorbed and retained solar energy with modern effectiveness, water at ancient Earth's surface would have been largely if not entirely frozen during this time, except where heated by magmatic and hydrothermal activity or beneath hundreds to thousands of meters of ice. Geologic evidence of ancient warm conditions is outlined below, followed by possible explanations for effective surface warming with a faint young Sun.

Archean strata deposited in shallow water with evidence of sunlit conditions indicate surface temperatures above freezing. These rock units include calcareous and siliceous strata interpreted as fossil microbial mats and mound-forming algal stromatolites that harbored, or were produced by, photosynthetic bacteria (e.g., Grotzinger and Knoll, 1999; Noffke, 2008; Tice et al., 2011). One of the oldest examples of aquatic microbial life is the 3.42 Ga Buck Reef Chert in South Africa, which contains carbonaceous layers, filaments, and grains deposited within finegrained, wave-agitated, siliceous sediments (Tice and Lowe, 2004) (Fig. 2D). The 3.35-3.43 Ga Strelley Pool Formation in the Pilbara Supergroup of northwestern Australia (Wacey et al., 2010) contains abundant evidence of microbial biofilms that precipitated carbonate and/or trapped fine detrital grains to form laminated stromatolites (Allwood et al., 2009; Wacey, 2010; Duda et al., 2016). Multiple associated sedimentary features in the Strelley Pool Formation, including rare desiccation cracks, indicate deposition in shallow-water, tidally affected, marine environments (e.g., Allwood et al., 2006). Fossil microbial mats and stromatolites resemble much younger and modern microbial mats, photosynthetic stromatolites, and cyanobacterial mounds

(Suosaari et al., 2016).

The abundance of sedimentary and fossil indicators of liquid water at Earth's surface during the Archean indicates the effectiveness of warming mechanisms that are still not well understood. $\mathrm{CO}_{2}$ and $\mathrm{N}_{2}$ were likely the dominant atmospheric gases (Kasting, 2014; Catling and Kasting, 2017). The absence of significant $\mathrm{O}_{2}$ in Earth's Archean atmosphere is indicated by unoxidized detrital sulfides and uraninite in Archean fluvial sediments (Rasmussen and Buick, 1999; Burron et al., 2018) and by sulfur isotopes in sedimentary rocks that were fractionated independent of mass by ultraviolet photolysis of $\mathrm{SO}_{2}$ in an anoxic atmosphere (Farquhar and Wing, 2003; Claire et al., 2014; Dauphas and Schauble, 2016). $\mathrm{CH}_{4}$ and $\mathrm{H}_{2}$ are potential greenhouse gases but would be slowly oxidized in such an atmosphere due to various reactions involving $\mathrm{H}_{2} \mathrm{O}$ and $\mathrm{CO}_{2}$ that are triggered by ultraviolet radiation, a process that would be more effective with more intense short-wavelength radiation in the Archean (Pavlov et al., 2001; Catling and Kasting, 2017). Methane could have been an important greenhouse gas, however, if methane-generating bacteria were abundant and if bacterial growth was not inhibited by cooling due to sunlight-shielding organic haze produced by photochemical reactions involving $\mathrm{CH}_{4}$ and $\mathrm{CO}_{2}$ (Domagal-Goldman et al., 2008). Effective warming by reducing greenhouse gases is suggested by the coincidence of earliest Proterozoic glaciations with the great oxidation event ("GOE") of Earth's atmosphere (Holland, 2006) (Fig. 2D). The GOE would have destroyed atmospheric $\mathrm{CH}_{4}$ and $\mathrm{H}_{2}$, thereby causing the temperature drop (Pavlov et al., 2000; Haqq-Misra et al., 2008).

Three-dimensional climate models of Archean Earth's atmosphere have been used to evaluate the effectiveness of several atmospheric variables that are important for a warm climate, including $\mathrm{CO}_{2}$, $\mathrm{CH}_{4}$, and $\mathrm{H}_{2}$ concentration, absolute pressure, and abundance of cloud-condensation nuclei. Warm, open-water conditions not unlike modern conditions were calculated for a 1-bar atmosphere with $1 \% \mathrm{CO}_{2}$ and $0.2 \% \mathrm{CH}_{4}$ at $2.5 \mathrm{Ga}$ (Charnay et al., 2013); $1.2 \% \mathrm{CO}_{2}$ and $0.1 \% \mathrm{CH}_{4}$ at $3.5 \mathrm{Ga}$ (Le Hir et al., 2014); and 0.1-0.36 bar $\mathrm{CO}_{2}$ partial pressure with 1 bar $\mathrm{N}_{2}$ at $3.8 \mathrm{Ga}$ (Charnay et al., 2017). A variety of other factors influence global temperature, including sea-ice dynamics and the abundance of cloud-droplet condensation nuclei. Appropriate values of multiple variables appear to be capable of warming Archean Earth to approximately modern temperatures, but the relative significance of these factors in supporting warm conditions under a faint young Sun has not been clearly identified.

\section{MARS}

The heavily cratered Noachian highlands of equatorial and southern Mars, 
which are the oldest exposed part of the martian crust, contain abundant evidence of erosion by water. Mars is freezing cold now and, with similar surface and atmospheric conditions, should have been even colder at 3-4 Ga. Some drainages are thousands of kilometers long and were fed by numerous tributaries that reached drainage divides in headwater regions (Howard et al., 2005; Hynek et al., 2010). Many rivers flowed into or through crater lakes, and some left delta deposits (Irwin et al., 2005; Fassett and Head, 2008b; Goudge et al., 2016). Calculations based on canyon width and depth indicate that canyons reflect $\sim 10^{3}-10^{7}$ years of erosion and were not incised by catastrophic outflows (Barnhart et al., 2009; Hoke et al., 2011; Rosenberg and Head, 2015). Precipitation, drainage incision, and crater-lake filling are inferred at ca. 3.3-3.9 Ga based on crater density in affected terrains (Fassett and Head, 2008a; Hoke and Hynek, 2009) (Fig. 2E).

Several factors would have supported warmer Noachian environmental conditions, although maybe not enough for precipitation and flowing water. The pressure of the modern martian atmosphere, at 6-10 millibars, is $\sim 1 \%$ that of Earth, but the ancient atmosphere was much thicker. The size and abundance of the smallest martian impact craters can be used to determine atmospheric pressure because the smallest meteorites are slowed or destroyed during passage through the atmosphere and so do not create impact craters. Size-frequency distributions for craters in fluvial deposits near Gale crater indicate that Noachian atmospheric pressure was in the range of 1-2 bars during heavy Noachian bombardment (Kite et al., 2014). Atmospheric pressure greater than a few hundred millibars results in a vertical temperature profile that approximates an adiabatic gradient (Wordsworth, 2016). Under such conditions, surface temperatures are lower at higher elevation, with potential accumulation of snow and ice at high elevations. Even if the atmosphere was pure $\mathrm{CO}_{2}$, however, this would not be adequate to warm early Mars to the point of supporting running water, especially in highland regions (Kasting, 1991; Forget et al., 2012).

Orbital factors relevant to early Mars climate are the variable tilt of its spin axis relative to the normal to the orbital plane (the obliquity) and the variable eccentricity (ellipticity) of the orbit. Earth's
Figure 3. (A) Obliquity of Mars at 2-6 Ma as calculated by Touma and Wisdom (1993). Note that obliquity exceeded $40^{\circ}$ at 5-6 Ma. (B) Probability of reaching high obliquities during the chaotic obliquity evolution of Mars over a range of time periods, with initial $25^{\circ}$ obliquity (from Laskar et al., 2004). (C) Total annual insolation versus latitude for obliquity variation of $0^{\circ}-90^{\circ}$. Insolation units are relative to the solar constant at $1.52 \mathrm{AU}$ (from Ward, 1974). (D) Normalized density function for chaotic eccentricity variation for Mars (from Figure 18d of Laskar et al., 2004). At present eccentricity, solar insolation at perihelion (orbital point closest to the Sun) is $45 \%$ greater than at aphelion.

obliquity is currently $23^{\circ}$, but because of stabilizing tidal forces associated with the Moon, obliquity varies over geologic time by $< \pm 2^{\circ}$ (Laskar et al., 1993). Mars, with current obliquity of $25^{\circ}$, does not have a massive moon, and its obliquity is not similarly stabilized. Because of tidal forces exerted on Mars by the Sun and planets, obliquity varied chaotically over millions of years to $>60^{\circ}$ (Figs. 3A and 3B) (Touma and Wisdom, 1993; Laskar et al., 2004). At obliquities $>\sim 45^{\circ}$, polar regions receive more sunlight than equatorial regions, potentially resulting in seasonal sublimation and evaporation at high latitudes and snow at low latitudes at times near summer solstices (Fig. 3C) (Ward, 1974; Jakosky and Carr, 1985; Wordsworth, 2016). High-latitude evaporation would be especially effective if the summer solstice coincided with greater proximity to the Sun during a period of high orbital eccentricity, which also varies chaotically (Fig. 3D).

Favorable obliquity and eccentricity, and a thick $\mathrm{CO}_{2}$ atmosphere, may have been adequate for evaporation and sublimation of ice at low elevations and accumulation of snow and ice at high elevations, but warmer conditions are needed to melt snow and ice at high elevations and produce runoff to carve river valleys and fill lakes in the Noachian highlands (Forget et al., 2012). Global climate models indicate that $1 \%-10 \%$ hydrogen and methane in a thick $\mathrm{CO}_{2}$ atmosphere could have elevated temperatures sufficiently to melt ice at high elevations (Wordsworth et al., 2017). These reduced gases are highly effective at absorbing infrared radiation that would otherwise leave the planet because of a process called "collision-induced absorption." In this process, extremely brief $\left(\sim 10^{-13} \mathrm{~s}\right)$ electrostatic interactions between colliding gas molecules $\left(\mathrm{CO}_{2}-\mathrm{H}_{2}\right.$ and $\mathrm{CO}_{2}-\mathrm{CH}_{4}$ in this case $)$
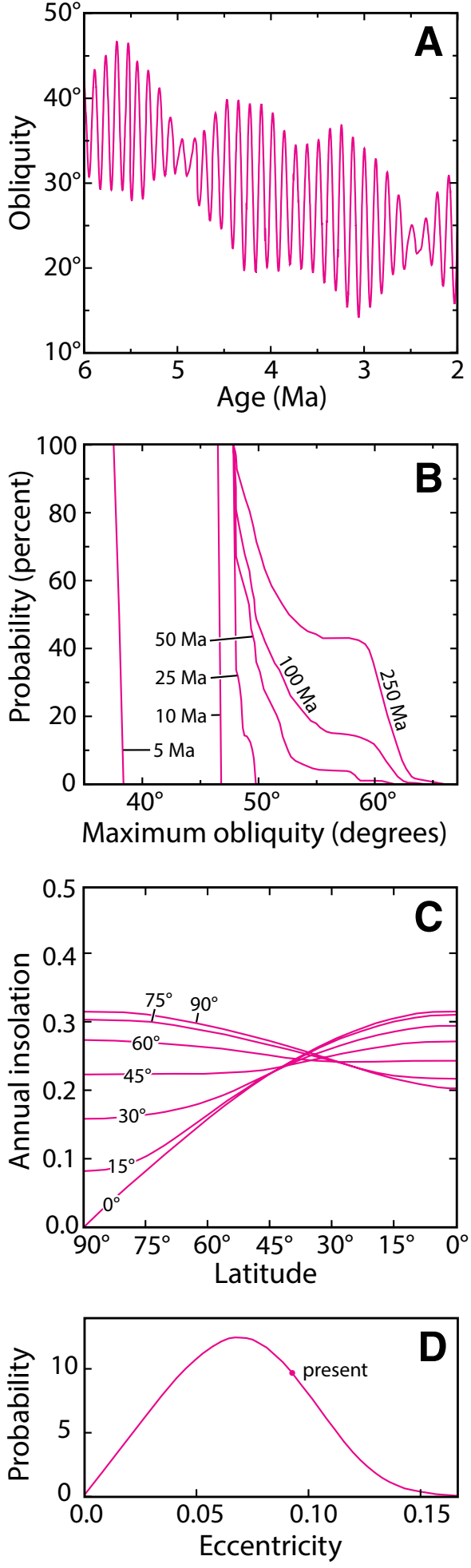

produce a weak bond in which the two gas molecules can absorb infrared radiation that would not be absorbed by the individual gas molecules. Collisioninduced absorption with these gases can potentially produce an early Mars atmosphere warm enough to cause melting and 
runoff from frozen martian highlands

(Wordsworth et al., 2017).

Multispectral imaging, lander observations, and the content of meteorites derived from Mars indicate that olivine is common on Mars (e.g., McSween et al., 2006; Koeppen and Hamilton, 2008; Ody et al., 2013). Hydrous alteration (serpentinization) of olivine and pyroxene by groundwater should have been common if not pervasive early in martian history (Oze and Sharma, 2005, 2007). Serpentinization yields $\mathrm{H}_{2}$, which in turn reacts with $\mathrm{CO}_{2}$ to produce $\mathrm{CH}_{4}$, as is seen in hydrothermal fluids associated with ultramafic rocks on Earth (Bradley and Summons, 2010). Cooling of the young martian crust in the presence of groundwater would result in formation of a near-surface cryosphere of frozen groundwater. Downward propagation of the boundary between frozen ground and deeper groundwater would trap dissolved methane in methane clathrate, which is water ice with $\sim 6 \%$ methane trapped within the cage-like molecular structure of the clathrate ice (e.g., Kvenvolden, 1993; Prieto-Ballesteros et al., 2006). As a result of clathrate genesis, the early martian cryosphere could have become a global methane reservoir (Lasue et al., 2015). Furthermore, the cryosphere would become an impermeable cap for trapped gaseous $\mathrm{H}_{2}$ and $\mathrm{CH}_{4}$, as on Earth (Kvenvolden, 1993).

Methane and hydrogen liberated to the atmosphere by cryosphere disruption and melting from magmatism, impacts, and perhaps outburst floods, would result in minor to perhaps significant transient planetary warming. Such warming might have been sufficient to cause snow and ice melting and runoff from Noachian highlands for perhaps tens to hundreds of thousands of years (Chassefière et al., 2016; Wordsworth et al., 2017), especially if it occurred during favorable orbital parameters (Palumbo et al., 2018). Such warming could melt more methane clathrate in a positive feedback cycle (Wordsworth et al., 2017). Finally, the $10^{5}-10^{7}$ years needed for river valley incision was perhaps the cumulative result of numerous short-lived warming episodes, each triggered by a different geologic event over hundreds of millions of years. It remains uncertain, however, if all these factors are adequate for melting and rivervalley incision on Mars.

\section{CONCLUSIONS}

1. Total solar-energy production is increasing gradually due to well-understood physics controlling rates of thermonuclear fusion in the solar core (Bahcall et al., 2001). A more massive and luminous young Sun is not supported by recent astrophysical studies.

2. Archean sedimentary rocks on Earth include many indicators of liquid water at Earth's surface, including sedimentary rocks containing evidence of microbial life that in turn indicate open water with sunlight. The warm Archean Earth resulted from high atmospheric concentrations of $\mathrm{CO}_{2}$, with possible additional warming from methane and hydrogen, lower cloud albedo, a low ratio of land to water at Earth's surface, and other factors. It is not clear which additional factors were dominant or if we are missing something fundamental.

3. Abundant evidence of martian river channels and crater lakes at ca. 3.3-3.9 $\mathrm{Ga}$ indicates warm conditions in otherwise icy highlands of equatorial and southern Mars. Although transient melting might occur under favorable orbital parameters, augmentation of such warming by a few percent atmospheric $\mathrm{H}_{2}$ and $\mathrm{CH}_{4}$ released from crustal or mantle reservoirs may be a viable solution to the faint young Sun problem for Mars.

\section{ACKNOWLEDGMENTS}

I thank James Kasting and an anonymous reviewer for comments that improved clarity and focus.

\section{REFERENCES CITED}

Allwood, A.C., Walter, M.R., Kamber, B.S., Marshall, C.P., and Burch, I.W., 2006 , Stromatolite reef from the Early Archaean era of Australia: Nature, v. 441, p. 714-718, https://doi.org/10.1038/nature04764.

Allwood, A.C., Grotzinger, J.P., Knoll, A.H., Burch, I.W., Anderson, M.S., Coleman, M.L., and Kanik, I., 2009, Controls on development and diversity of early Archean stromatolites: Proceedings of the National Academy of Sciences of the United States of America, v. 106 , no. 24 , p. 9548-9555, https://doi.org/ 10.1073/pnas.0903323106.

Ayres, T.R., 1997, Evolution of the solar ionizing flux: Journal of Geophysical Research, v. 102, E1, p. 1641-1651, https://doi.org/10.1029/96JE03306.

Bahcall, J.N., Pinsonneault, M.H., and Basu, S., 2001, Solar models: Current epoch and time dependences, neutrinos, and helioseismological properties: The Astrophysical Journal, v. 555, p. 990-1012, https://doi.org/10.1086/321493.
Barnhart, C.J., Howard, A.D., and Moore, J.M., 2009, Long-term precipitation and latestage valley network formation: Landform simulations of Parana Basin, Mars: Journal of Geophysical Research, v. 114, E01003, https:// doi.org/10.1029/2008JE003122.

Bradley, A., and Summons, R.E., 2010, Multiple origins of methane at the Lost City Hydrothermal Field: Earth and Planetary Science Letters, v. 297, p. 34-41, https://doi.org/ 10.1016/j.epsl.2010.05.034.

Burbidge, E.M., Burbidge, G.R., Fowler, W.A., and Hoyle, F., 1957, Synthesis of the elements in stars: Reviews of Modern Physics, v. 29, no. 4, p. 547-650, https://doi.org/10.1103/ RevModPhys.29.547.

Burron, I., da Costa, G., Sharpe, R., Fayek, M., Gauert, C., and Hofmann, A., 2018, 3.2 Ga detrital uraninite in the Witwatersrand Basin, South Africa: Evidence of a reducing Archean atmosphere: Geology, v. 46, p. 295-298, https://doi.org/10.1130/G39957.1.

Catling, D.C., and Kasting, J.F., 2017, Atmospheric Evolution on Inhabited and Lifeless Worlds: New York, Cambridge University Press, 579 p., https://doi.org/10.1017/9781139020558.

Charnay, B., Forget, F., Wordsworth, R., Leconte, J., Millour, E., Codron, F., and Spiga, A., 2013, Exploring the faint young Sun problem and the possible climates of the Archean Earth with a 3-D GCM: Journal of Geophysical Research, v. 118, p. 10,414-10,431, doi:10.1002/jgrd.50808.

Charnay, B., Le Hir, G., Fluteau, F., Forget, F. and Catling, D.C., 2017, A warm or a cold early Earth? New insights from a 3-D climate-carbon model: Earth and Planetary Science Letters, v. 474, p. 97-109, https:// doi.org/10.1016/j.eps1.2017.06.029.

Chassefière, E., Lasue, J., Langlais, B., and Quesnel, Y., 2016, Early Mars serpentinizationderived $\mathrm{CH}_{4}$ reservoirs, $\mathrm{H}_{2}$-induced warming and paleopressure evolution: Meteoritics \& Planetary Science, v. 51, no. 11, p. 2234-2245, https://doi.org/10.1111/maps.12784.

Claire, M.W., Kasting, J.F., Domagal-Goldman, S.D., Stüeken, E.E., Buick, R., and Meadows, V.S., 2014, Modeling the signature of sulfur mass-independent fractionation produced in the Archean atmosphere: Geochimica et Cosmochimica Acta, v. 141, p. 365-380, https://doi.org/10.1016/j.gca.2014.06.032.

Dauphas, N., and Schauble, E.A., 2016, Mass fractionation laws, mass-independent effects, and isotopic anomalies: Annual Review of Earth and Planetary Sciences, v. 44, p. 709-783, https://doi.org/10.1146/annurev -earth-060115-012157.

de Wit, M.J., and Furnes, H., 2016, 3.5-Ga hydrothermal fields and diamictites in the Barberton Greenstone Belt_-Paleoarchean crust in cold environments: Science Advances, v. 2, no. 2, e1500368, https://doi.org/10.1126/ sciadv. 1500368 .

Domagal-Goldman, S.D., Kasting, J.F., Johnston, D.T., and Farquhar, J., 2008, Organic haze, glaciations and multiple sulfur isotopes in the Mid-Archean Era: Earth and Planetary Science Letters, v. 269, p. 29-40, https:// doi.org/10.1016/j.epsl.2008.01.040.

Duda, J.-P., Van Kranendonk, M.J., Thiel, V., Ionescu, D., Strauss, H., Schäfer, N., and 
Reitner, J., 2016, A rare glimpse of Paleoarchean life: Geobiology of an exceptionally preserved microbial mat facies from the 3.4 Ga Strelley Pool Formation, Western Australia: PLoS One, v. 11, no. 1, https:// doi.org/10.1371/journal.pone.0147629.

Farquhar, J., and Wing, B.A., 2003, Multiple sulfur isotopes and the evolution of the atmosphere: Earth and Planetary Science Letters, v. 213, p. 1-13, https://doi.org/ 10.1016/S0012-821X(03)00296-6.

Fassett, C.I., and Head, J.W., III, 2008a, The timing of martian valley network activity: Constraints from buffered crater counting: Icarus, v. 195, p. 61-89, https://doi.org/ 10.1016/j.icarus.2007.12.009.

Fassett, C.I., and Head, J.W., III, 2008b, Valley network-fed, open-basin lakes on Mars: Distribution and implications for Noachian surface and subsurface hydrology: Icarus, v. 198, p. 37-56, https://doi.org/10.1016/ j.icarus.2008.06.016.

Fassett, C.I., and Head, J.W., III, 2011, Sequence and timing of conditions on early Mars: Icarus, v. 211, p. 1204-1214, https://doi.org/ 10.1016/j.icarus.2010.11.014.

Feulner, G., 2012, The faint young Sun problem: Reviews of Geophysics, v. 50, RG2006, https://doi.org/10.1029/2011RG000375.

Forget, F., Wordsworth, R., Millour, E., Madeleine, J.-B., Kerber, L., Leconte, J., Marcq, E., and Haberle, R.M., 2012, 3D modelling of the early martian climate under a denser $\mathrm{CO}_{2}$ atmosphere: Temperatures and $\mathrm{CO}_{2}$ ice clouds: Icarus, v. 222, p. 81-99, https://doi.org/10.1016/j.icarus.2012.10.019.

Gallet, F., and Bouvier, J., 2015, Improved angular momentum evolution model for solar-like stars II. Exploring the mass dependence: Astronomy \& Astrophysics, v. 577, A98, https://doi.org/10.1051/0004-6361/ 201525660

Goudge, T.A., Fassett, C.I., Head, J.W., Mustard, J.F., and Aureli, K.L., 2016, Insights into surface runoff on early Mars from paleolake basin morphology and stratigraphy: Geology, v. 44 , no. 6 , p. 419-422, https://doi.org/ 10.1130/G37734.1.

Gough, D.O., 1981, Solar interior structure and luminosity variations: Solar Physics, v. 74, p. 21-34, https://doi.org/10.1007/BF00151270.

Grotzinger, J.P., and Knoll, A.H., 1999, Stromatolites in Precambrian carbonates: Evolutionary mileposts or environmental dipsticks?: Annual Review of Earth and Planetary Sciences, v. 27, p. 313-358, https://doi.org/10.1146/annurev .earth.27.1.313.

Haqq-Misra, J.D., Domagal-Goldman, S.D., Kasting, P.J., and Kasting, J.F., 2008, A revised, hazy methane greenhouse for the Archean Earth: Astrobiology, v. 8, no. 6, p. 1127-1137, https://doi.org/10.1089/ast.2007.0197.

Hartman, J.D., Gaudi, B.S., Pinsonneault, M.H., Stanek, K.Z., Holman, M.J., McLeod, B.A., Meibom, S., Barranco, J.A., and Kalirai, J.S., 2009, Deep MMT transit survey of the open cluster M37. III. Stellar rotation at $550 \mathrm{Myr}$ : The Astrophysical Journal, v. 691, p. 342-364, https://doi.org/10.1088/0004-637X/691/1/342.

Haxton, W.C., Robertson, R.G.H., and Serenelli, A.M., 2013, Solar neutrinos: Status and prospects: Annual Review of Astronomy and Astrophysics, v. 51, p. 21-61, https://doi.org/ 10.1146/annurev-astro-081811-125539.

Hoke, M.R.T., and Hynek, B.M., 2009, Roaming zones of precipitation on ancient Mars as recorded in valley networks: Journal of Geophysical Research, v. 114, E08002, https://doi.org/10.1029/2008JE003247.

Hoke, M.R.T., Hynek, B.M., and Tucker, G.E., 2011, Formation timescales of large martian valley networks: Earth and Planetary Science Letters, v. 312, p. 1-12, https://doi.org/10.1016/ j.epsl.2011.09.053.

Holland, H.D., 2006, The oxygenation of the atmosphere and oceans: Philosophical Transactions of the Royal Society of London, Series B, Biological Sciences, v. 361, p. 903915, https://doi.org/10.1098/rstb.2006.1838.

Howard, A.D., Moore, J.M., and Irwin, R.P., III, 2005, An intense terminal epoch of widespread fluvial activity on early Mars: 1 . Valley network incision and associated deposits: Journal of Geophysical Research, v. 110, E12S14, https://doi.org/10.1029/2005JE002459.

Hynek, B.M., Beach, M., and Hoke, M.R.T., 2010, Updated global map of martian valley networks and implications for climate and hydrologic processes: Journal of Geophysical Research, v. 115, E09008, https://doi.org/10.1029/ 2009JE003548

Irwin, R.P., III, Howard, A.D., Craddock, R.A., and Moore, J.M., 2005, An intense terminal epoch of widespread fluvial activity on early Mars: 2. Increased runoff and paleolake development: Journal of Geophysical Research, v. 110, E12S15, https://doi.org/ 10.1029/2005JE002460.

Jakosky, B.M., and Carr, M.H., 1985, Possible precipitation of ice at low latitudes of Mars during periods of high obliquity: Nature, v. 315, p. 559-561, https://doi.org/10.1038/315559a0.

Kasting, J.F., 1991, CO 2 condensation and the climate of early Mars: Icarus, v. 94, p. 1-13, https://doi.org/10.1016/0019-1035(91)90137-I.

Kasting, J.F., 2014, Atmospheric composition of Hadean-early Archean Earth: The importance of CO, in Shaw, G.H., ed., Earth's Early Atmosphere and Surface Environment: Geological Society of America Special Paper 504, p. 19-28, https://doi.org/10.1130/ 2014.2504(04).

Kite, E.S., Williams, J.-P., Lucas, A., and Aharonson, O., 2014, Low palaeopressure of the martian atmosphere estimated from the size distribution of ancient craters: Nature Geoscience, v. 7, no. 5, p. 335-339, https:// doi.org/10.1038/ngeo2137.

Koeppen, W.C., and Hamilton, V.E., 2008, Global distribution, composition, and abundance of olivine on the surface of Mars from thermal infrared data: Journal of Geophysical Research, v. 113, E05001, https://doi.org/10.1029/2007JE002984.

Kvenvolden, K.A., 1993, A primer on gas hydrates, in Howell, D.G., ed., The Future of Energy Gases: U.S. Geological Survey Professional Paper 1570, p. 279-291.

Laskar, J., Joutel, F., and Robutel, P., 1993, Stabilization of the Earth's obliquity by the Moon: Nature, v. 361, p. 615-617, https:// doi.org/10.1038/361615a0.
Laskar, J., Correia, A.C.M., Gastineau, M., Joutel, F., Levrard, B., and Robutel, P., 2004, Long term evolution and chaotic diffusion of the insolation quantities of Mars: Icarus, v. 170, p. 343-364, https://doi.org/10.1016/ j.icarus.2004.04.005.

Lasue, J., Quesnel, Y., Langlais, B., and Chassefière, E., 2015, Methane storage capacity of the early martian cryosphere: Icarus, v. 260, p. $205-214$, https://doi.org/10.1016/j.icarus .2015.07.010.

Le Hir, G., Teitler, Y., Fluteau, F., Donnadieu, Y., and Philippot, P., 2014, The faint young Sun problem revisited with a 3-D climate-carbon modelPart 1: Climate of the Past, v. 10, p. 697-713, https://doi.org/10.5194/cp-10-697-2014.

McSween, H.Y., and 41 others, 2006, Characterization and petrologic interpretation of olivine-rich basalts at Gusev Crater, Mars: Journal of Geophysical Research, v. 111, E02S10, https://doi.org/10.1029/2005JE002477.

Meibom, S., Mathieu, R.D., and Stassun, K.G., 2009, Stellar rotation in M35: Mass-period relations, spin-down rates, and gyrochronology: The Astrophysical Journal, v. 695, p. 679-694, https://doi.org/10.1088/0004 $-637 \mathrm{X} / 695 / 1 / 679$.

Meibom, S., and 19 others, 2011, The Kepler cluster study: Stellar rotation in NGC 6811: The Astrophysical Journal, Letters, v. 733, https://doi.org/10.1088/2041-8205/733/1/L9.

Meibom, S., Barnes, S.A., Platais, I., Gilliland, R.L., Latham, D.W., and Mathieu, R.D., 2015, A spin-down clock for cool stars from observations of a 2.5-billion-year-old cluster: Nature, v. 517, p. 589-591, https://doi.org/ 10.1038/nature14118.

Minton, D.A., and Malhotra, R., 2007, Assessing the massive young Sun hypothesis to solve the warm young Earth puzzle: The Astrophysical Journal, v. 660, p. 1700-1706, https://doi.org/ $10.1086 / 514331$.

Noffke, N., 2008, Turbulent lifestyle: Microbial mats on Earth's sandy beaches-Today and 3 billion years ago: GSA Today, v. 18 , no. 10 , p. 4-9, https://doi.org/10.1130/GSATG7A.1.

Ody, A., Poulet, F., Bibring, J.-P., Loizeau, D., Carter, J., Gondet, B., and Langevin, Y., 2013, Global investigation of olivine on Mars: Insights into crust and mantle compositions: Journal of Geophysical Research, Planets, v. 118, p. 234-262, https://doi.org/10.1029/ 2012JE004149.

Ojakangas, R.W., Srinivasan, R., Hegde, V.S., Chandrakant, S.M., and Srikantia, S.V., 2014, The Talya Conglomerate: An Archean $(\sim 2.7$ $\mathrm{Ga})$ glaciomarine formation, western Dharwar craton, southern India: Current Science, v. 106 , p. $387-396$.

Oze, C., and Sharma, M., 2005, Have olivine, will gas: Serpentinization and the abiogenic production of methane on Mars: Geophysical Research Letters, v. 32, L10203, https:// doi.org/10.1029/2005GL022691.

Oze, C., and Sharma, M., 2007, Serpentinization and the inorganic synthesis of $\mathrm{H}_{2}$ in planetary surfaces: Icarus, v. 186, p. 557-561, https:// doi.org/10.1016/j.icarus.2006.09.012.

Palumbo, A.M., Head, J.W., and Wordsworth, R.D., 2018, Late Noachian Icy Highlands climate model: Exploring the possibility of 
transient melting and fluvial/lacustrine activity through peak annual and seasonal temperatures: Icarus, v. 300, p. 261-286, https://doi.org/10.1016/j.icarus.2017.09.007.

Pavlov, A.A., Kasting, J.F., Brown, L.L., Rages, K.A., and Freedman, R., 2000, Greenhouse warming by $\mathrm{CH}_{4}$ in the atmosphere of early Earth: Journal of Geophysical Research, v. 105, E5, p. 11,981-11,990, https://doi.org/ 10.1029/1999JE001134.

Pavlov, A.A., Brown, L.L., and Kasting, J.F., 2001, UV shielding of $\mathrm{NH}_{3}$ and $\mathrm{O}_{2}$ by organic hazes in the Archean atmosphere: Journal of Geophysical Research, v. 106, E10, p. 23,26723,287, https://doi.org/10.1029/2000JE001448.

Prieto-Ballesteros, O., Kargel, J.S., Fairén, A.G., Fernández-Remolar, D.C., Dohm, J.M., and Amils, R., 2006, Interglacial clathrate destabilization on Mars: Possible contributing source of its atmospheric methane: Geology, v. 34, no. 3, p. 149-152, https://doi.org/10.1130/ G22311.1.

Rasmussen, B., and Buick, R., 1999, Redox state of the Archean atmosphere: Evidence from detrital heavy minerals in ca. 3250-2750 Ma sandstones from the Pilbara craton, Australia: Geology, v. 27 , p. $115-118$, https://doi.org/10.1130/ 0091-7613(1999)027<0115:RSOTAA >2.3.CO;2.

Rebull, L.M., and 18 others, 2016, Rotation in the Pleiades with K2. I. Data and first results: The Astronomical Journal, v. 152, https://doi.org/ 10.3847/0004-6256/152/5/113.

Rebull, L.M., Stauffer, J.R., Hillenbrand, L.A., Cody, A.M., Bouvier, J., Soderblom, D.R., Pinsonneault, M., and Hebb, L., 2017, Rotation of late-type stars in Praesepe with K2: The Astrophysical Journal, v. 829, https://doi.org/ 10.3847/1538-4357/aa6aa4.

Ribas, I., Guinan, E.F., Güdel, M., and Audard, M., 2005, Evolution of the solar activity over time and effects on planetary atmospheres. I. High-energy irradiances (1-1700 ̊): The Astrophysical Journal, v. 622, p. 680-694, https://doi.org/10.1086/427977.
Rosenberg, E.N., and Head, J.W., III, 2015, Late Noachian fluvial erosion on Mars: Cumulative water volumes required to carve the valley networks and grain size of bed-sediment: Planetary and Space Science, v. 117, p. 429-435, https://doi.org/10.1016/j.pss.2015.08.015.

Sackmann, I.-J., and Boothroyd, A.I., 2003, Our Sun. V. A bright young Sun consistent with helioseismology and warm temperatures on ancient Earth and Mars: The Astrophysical Journal, v. 583, p. 1024-1039, https://doi.org/ 10.1086/345408.

Sagan, C., and Mullen, G., 1972, Earth and Mars: Evolution of atmospheres and surface temperatures: Science, v. 177, p. 52-56, https://doi.org/10.1126/science.177.4043.52.

Skumanich, A., 1972, Time scales for Ca II emission decay, rotational braking, and lithium depletion: The Astrophysical Journal, v. 171, p. 565-567, https://doi.org/10.1086/151310.

Suosaari, E.P., Reid, R.P., Playford, P.E., Foster, J.S., Stoltz, J., Casaburi, G., Hagan, P., Chirayath, V., Macintyre, I., Planavsky, N., and Eberli, G.P., 2016, New multi-scale perspectives on the stromatolites of Shark Bay, Western Australia: Scientific Reports, v. 6, p. 20,557, https://doi.org/10.1038/srep20557.

Tice, M.M., and Lowe, D.R., 2004, Photosynthetic microbial mats in the 3,416-Myr-old ocean: Nature, v. 431, p. 549-552, https:// doi.org/10.1038/nature02888.

Tice, M.M., Thornton, D.C.O., Pope, M.C., Olszewski, T.D., and Gong, J., 2011, Archean microbial mat communities: Annual Review of Earth and Planetary Sciences, v. 39, p. 297-319, https://doi.org/10.1146/annurev -earth-040809-152356.

Touma, J., and Wisdom, J., 1993, The chaotic obliquity of Mars: Science, v. 259, p. 1294-1297, https://doi.org/10.1126/science.259.5099.1294.

Ulrich, R.K., 1975, Solar neutrinos and variations in the solar luminosity: Science, v. 190, p. 619-624, https://doi.org/10.1126/science .190.4215.619.
Wacey, D., 2010, Stromatolites in the $\sim 3400 \mathrm{Ma}$ Strelley Pool Formation, Western Australia: Examining biogenicity from the macro- to the nano-scale: Astrobiology, v. 10, no. 4, p. 381-395, https://doi.org/10.1089/ast.2009.0423.

Wacey, D., McLoughlin, N., Stoakes, C.A., Kilburn, M.R., Green, O.R., and Brasier, M.D., 2010, The 3426-3350 Ma Strelley Pool Formation in the East Strelley greenstone belt-A field and petrographic guide: Geological Survey of Western Australia, Record 2010/10, 64 p.

Ward, W.R., 1974, Climatic variation on Mars 1. Astronomical theory of insolation: Journal of Geophysical Research, v. 79, no. 24, p. 33753386, https://doi.org/10.1029/JC079i024p03375.

Whitmire, D.P., Doyle, L.R., Reynolds, R.T., and Matese, J.J., 1995, A slightly more massive young Sun as an explanation for warm temperatures on early Mars: Journal of Geophysical Research, v. 100, E3, p. 54575464, https://doi.org/10.1029/94JE03080.

Wordsworth, R.D., 2016, The climate of early Mars: Annual Review of Earth and Planetary Sciences, v. 44, p. 381-408, https://doi.org/ 10.1146/annurev-earth-060115-012355.

Wordsworth, R., Kalugina, Y., Lokshtanov, S., Vigasin, A., Ehlmann, B., Head, J., Sanders, C., and Wang, H., 2017, Transient reducing greenhouse warming on early Mars: Geophysical Research Letters, v. 44, p. 665-671, https://doi.org/10.1002/2016GL071766.

Young, G.M., von Brunn, V., Gold, D.J.C., and Minter, W.E.L., 1998, Earth's oldest reported glaciation: Physical and chemical evidence from the Archean Mozaan Group ( 2.9 Ga) of South Africa: The Journal of Geology, v. 106, p. 523-538, https://doi.org/10.1086/516039.

ManusCript Received 24 Feb. 2019 REVISED MANUSCRIPT RECEIVED 30 APR. 2019 MANUSCRIPT ACCEPTED 13 JunE 2019 